\title{
SENTIDOS DA ATIVIDADE DE AVALIAR: \\ A FORMAÇÃO DE PROFESSORES EM \\ PERSPECTIVA DISCURSIVA
}

\author{
DEUSDARÁ, Bruno \\ GIORGI, Maria Cristina
}

\section{INTRODUÇÃO}

Os temas da Educação têm ganhado relevo considerável na atualidade. O tratamento conferido a esses temas vem colocando em destaque políticas públicas que, pretensamente, procurariam favorecer a "mobilização social" em torno da "melhoria da qualidade". Atravessando desde decretos presidenciais a spots publicitários da grande imprensa e grupos empresariais, a cena consolidada levaria a crer que a solução estaria em alcançar "índices de qualidade" desejáveis.

Encontramo-nos diante de um impasse: a mobilização social em torno da qualidade, segundo indicada nos decretos do Plano de Desenvolvimento da Educação (PDE), dá-se nos marcos de metas já elaboradas. Uma vez colocados os patamares a serem alcançados, o foco recai sobre o trabalho do professor como aquele que agencia "com sucesso" saberes repetidos nas provas com objetivo de aferir "índices de qualidade". Já há expectativas de que aluno se deseja ver formado, que conteúdos são valorizados, circulando nas avaliações nacionais.

Bons professores, nesse quadro, são aqueles que multiplicam as tarefas dos alunos, investem nos reforços e nas listas de repetição dos conteúdos. Bom aprendiz é aquele que se aplica em repetir e acertar tudo. O certo é apenas o que corresponde ao esperado nas avaliações nacionais. Pensar de outra maneira torna-se perda de tempo e... ousadia frente aos dispositivos de controle!

A temática da formação de professores ganha contornos rígidos. Segundo esse imperativo do cumprimento das metas, espera- 
se do professor agilidade com cronogramas, identificação de possíveis deficiências, aplicação de tarefas de reforço. Fala-se muito em cursos de formação continuada, capacitação para agilizar a aquisição de conteúdos e identificar mais facilmente o que destoa ao ritmo dos cronogramas. Enfatiza-se uma dimensão de execução no cotidiano do trabalho do professor, em detrimento de interrogar a eficácia dos índices, a precariedade de infraestrutura, a desvalorização salarial grave. O cotidiano passa a ser apenas o momento de cumprir um já pensado, sem condições para fazer da própria prática profissional fonte de saberes para o professor.

No entanto, sabemos que tais propostas não são inovações das políticas públicas atuais, tais dispositivos de controle compõem a tradição escolar. Há uma parte disso tudo que atravessa nossas práticas cotidianas. É essa a contribuição pretendida por este artigo, quando analisamos dois materiais em que o professor é avaliado / convocado a avaliar: prova de concurso de seleção de professores para rede pública de ensino e um formulário-ata de Conselho de Classe, utilizado em uma escola da rede pública estadual do Rio de Janeiro.

As ferramentas conceituais provêm da articulação entre a reflexão acerca dos gêneros do discurso (BAKHTIN, 2000) e a compreensão do cotidiano como produção permanente, configurandose de relações de poder que geram saberes (FOUCAULT, 2004). Nosso intuito residiria em inverter o fluxo tradicional dos saberes como unicamente aprendidos antes ou fora da prática profissional, restringindo-a à sua aplicação.

\section{AS PRÁTICAS DE AVALIAÇÃO EM DISCUSSÃO: CONSTRUINDO EXPECTATIVAS SOBRE O TRABALHO DOCENTE}

Ao propor a discussão em torno de dois materiais a partir dos quais o professor é avaliado / convocado a avaliar, consideramos 
necessário refletir acerca dos sentidos de avaliar. Os sentidos possivelmente atribuídos ao verbo avaliar, em língua portuguesa, deslocam-se entre "determinar o valor de algo", "reconhecer seus méritos", "calcular sua força, intensidade". O ato de avaliar, ou melhor, de determinar, reconhecer ou calcular o valor, os méritos ou a intensidade de algo ou alguém, parece estar presente em diversos momentos de nossas vidas.

Quando assistimos à emergência de avaliações nacionais, observa-se a apropriação de dispositivos pertencentes aos rituais e às tradições escolares acentuando concorrências e acelerações próprias a políticas neoliberalizantes. A esse respeito, Deise Mancebo e Marisa Rocha (2002) destacam que as práticas de avaliação vêm sendo reforçadas no Brasil, a partir dos anos oitenta, no Ensino Superior, atendendo a anseios contraditórios. No entanto, é a dimensão empresarial que dá o tom das práticas de avaliação nas políticas públicas.

Reformar a escola, reformar a indústria, o hospital, o exército, a prisão; mas todos sabemos que essas instituições estão condenadas, num prazo mais ou menos longo. Trata-se apenas de gerir sua agonia e ocupar as pessoas, até a instalação das novas forças que se anunciam (DELEUZE, 2006, p. 220).

"É preciso salvar a escola", dizem os burocratas de plantão! A "solução" oferecida vem sendo experimentada há mais de duas décadas pelas Universidades brasileiras, cuja insistência favorece o aparecimento de uma "cultura da avaliação":

A cultura da avaliação na realidade da universidade brasileira está no bojo das políticas neoliberais que se farão sentir a partir da década de 90 do último século, constituindo-se em aprimoramento do racionalismo cientificista consolidado ao longo da era moderna: conhecimento técnico, objetividade, princípios ligados a leis naturais, parâmetros neutros e universais. Tais políticas não estão desvinculadas 
das estratégias governamentais constituídas para lidar com a crise mundial do capitalismo que, entre nós, agravará a precariedade de funcionamento das instituições sociais (ROCHA, M.; ROCHA, D., 2004, p. 20).

A "solução" apontada sustenta-se em uma técnica bastante enraizada na tradição escolar. Trata-se do exame, que combina hierarquia e sanção normalizadora, que permite qualificar, classificar e punir, ou seja, distinguir e sancionar (FOUCAULT, 2005).

$\mathrm{Na}$ história dessas instituições, ganha força um ritual em torno dos dispositivos de avaliação que "colam" os resultados alcançados aos corpos de cada um. Os alunos designam-se uns aos outros e a si próprios da seguinte maneira: "eu sou um aluno sete em Matemática" ou "eu sou cinco em Português". Quando se diz "eu sou sete", o resultado obtido passar a revelar algo que supõe ser sua capacidade, tomada independente das condições de realização, da parcialidade dos conteúdos exigidos nessas aferições. Quem é visível então não é o poder, e sim o sujeito vigiado. Para que o indivíduo seja controlado, é preciso conhecer seus traços particulares. Cria-se um sistema comparativo que possibilita a aferição de fenômenos globais. $O$ observado é induzido a um estado consciente e permanente de visibilidade, que permite e proporciona o funcionamento do poder.

Colocar em tensionamento as "avaliações de desempenho" que têm sustentado as políticas públicas para a Educação significa apostar numa discussão sobre as práticas de avaliação e seus efeitos em nós.

Dessa forma, caberia destacar os seguintes questionamentos:

Para disciplinar e controlar, a escola faz uso do mecanismo da avaliação, também recoberto de mil argumentos didático-pedagógicos, mas outra marca indelével do poder e do controle. Ora, dirão alguns, como educar se não tivermos um feedback dos alunos, só possível através dos mais diversos mecanismos de avaliação, para reorganizar continuamente o processo pedagógico? (GALLO, 2008, p. 82-83). 
O mesmo dirão os administradores públicos: é preciso conhecer as escolas para administrá-las melhor. As críticas ao fortalecimento dos dispositivos de avaliação como estratégias de controle do trabalho do professor, produzindo como efeitos a perda de sentido dos vínculos e a desvalorização dos encontros sempre únicos que acontecem nas salas de aula entre professor, aluno e conhecimento, não pode, por outro lado, deixar de considerar que tais dispositivos compõem a tradição e os rituais das instituições de formação.

Nessa discussão privilegiamos a constituição de saberes e de imagens discursivas de trabalhador docente a partir da análise de textos que remetem à atividade de avaliar, por compreendermos que esta é constitutiva do trabalho docente, quer quando aplicamos provas ou nos submetemos a elas, quer quando, em sentido mais amplo, analisamos percursos e, a partir deles, elaboramos alternativas.

Para desnaturalização das próprias práticas que lhes dão sustentação, buscamos associar a proposta de relação poder-saber de Foucault com as estratégias de exercício de poder observadas nos textos aqui analisados, visando a colocar em relevo os saberes da atividade docente que não apenas os da sala de aula.

\section{GÊNEROS DO DISCURSO EM DEBATE: APREENDENDO MANEIRAS DE AGIR ATRAVÉS DA PRODUÇÃO VERBAL}

A noção de gênero do discurso em Bakhtin articula as realizações da língua e as esferas da atividade às quais estão vinculadas, observando a elaboração de "tipos relativamente estáveis de enunciados" (BAKHTIN, 2000, p. 280). A relativa estabilidade das realizações linguísticas é fenômeno situado indissociavelmente às diversas esferas da atividade humana. "A utilização da língua efetuase em forma de enunciados (orais ou escritos), concretos e únicos, 
que emanam dos integrantes duma ou doutra esfera da atividade humana" (BAKHTIN, 2000, p. 280).

O referido autor oferece ainda três componentes do todo de um gênero do discurso: o conteúdo temático, o estilo e a construção composicional. Para Bakhtin, esses tipos relativamente estáveis - os gêneros do discurso - permitem ao interlocutor assumir posição ativa na interação. A compreensão do gênero a que pertencem os enunciados confere às produções de linguagem um acabamento, que possibilita a troca na interação verbal.

É necessário o acabamento para tornar possível uma reação ao enunciado. Não basta que 0 enunciado seja inteligível no nível da língua. Uma oração totalmente inteligível e acabada, se for uma oração e não um enunciado - constituído de uma única oração - não poderá suscitar uma reação de resposta: é inteligível, está certo, mas ainda não é um todo (BAKHTIN, 2000, p. 299).

O interlocutor, para Bakhtin, assume uma postura de compreensão responsiva ativa. A compreensão possui uma dimensão de resposta. Ao concordar, discordar, completar, interromper, retirarse, o coenunciador manifesta-se ativamente.

Ressignifica-se a relação entre os interlocutores nas trocas verbais:

o próprio locutor como tal é, em certo grau, um respondente, pois não é o primeiro locutor, que rompe pela primeira vez o eterno silêncio de um mundo mudo, e pressupõe não só a existência do sistema da língua que utiliza, mas também a existência dos enunciados anteriores - emanantes dele mesmo ou do outro - aos quais seu próprio enunciado está vinculado por algum tipo de relação (...) (BAKHTIN, 2000, p. 291).

Motivado por insuficiências da oposição entre as tipologias enunciativas - que não levam em conta a inscrição social da atividade verbal - as tipologias comunicacionais / situacionais - que não 
consideram o funcionamento linguístico dos textos, Maingueneau (2001) propõe cinco critérios para conceber um gênero:

uma finalidade reconhecida;

o estatuto de parceiros legítimos;

o lugar e o momento legítimos;

um suporte material;

uma organização textual.

A noção de gênero de discurso assim compreendida possibilita a apreensão do encontro indissolúvel dos enunciados e de seu contexto dialógico, superando o problema clássico da relação entre a linguagem e seu entorno a partir da dicotomia lingüístico / extralinguístico.

Por contexto dialógico, Bakhtin entende não apenas a situação concreta imediata, como também o contexto sócio-histórico mais geral. A título de exemplo, diríamos que, através de um texto produzido em situação de interação professor-aluno em sala de aula, apresentam-se conteúdos, explicitam-se suas relações com outros conceitos, explicam-se possíveis operações em jogo com ele, propõese um exercício de aplicação / utilização desses conteúdos. Isso não se realiza sem que uma dada qualidade de relação se estabeleça entre os participantes dessa situação de troca verbal. Já assistimos a muitas aulas, já sabemos como nos colocar nelas, mas há ainda uma parte dessas relações que está em jogo cada vez que entramos em sala, sua condução está em disputa e o texto produzido em aula é uma das dimensões em que tal disputa ganha materialidade.

Entende-se assim que

(...) a relação dialógica é uma relação (de sentido) que se estabelece entre enunciados na comunicação verbal. Dois enunciados quaisquer, se justapostos no plano do sentido (não como objeto ou exemplo lingüístico), entabularão uma relação dialógica (BAKHTIN, 2000, p.346). 
Aqui, evidenciamos como as ferramentas de Bakhtin podem ser úteis na análise de uma dimensão micropolítica das trocas verbais. Apenas em aparência uma avaliação poria em cena alguém responsável pela elaboração das perguntas e outro que teria a tarefa de respondê-las. Entendemos que a análise dos gêneros do discurso constitutivos do fazer docente é, portanto, uma possibilidade de apreensão das diversas atividades que atravessam esse fazer. A partir dos gêneros, podemos indicar os diferentes lugares institucionalizados previstos para o trabalhador-professor e um conjunto de expectativas.

Neste artigo, os textos selecionados para análise remetem a uma esfera da atividade tão marcada como integrante do trabalho docente: a atividade de avaliar. Passemos à descrição do material analisado, para, no próximo item, proceder a um levantamento de pontos de contato e de afastamento entre eles.

a prova de seleção ${ }^{6}$,

As provas de seleção indicam, no contexto atual de nossa realidade educacional, aquilo que os profissionais precisam saber. Acabam por funcionar como referencial a ser seguido por aqueles que pretendem ingressar na rede pública de ensino, podendo, inclusive, influenciar cursos de formação. São, portanto, uma dupla memória que remete ao passado - reproduzindo e mantendo o que vem ou não sendo privilegiado - e aponta para o futuro - prescrevendo o que deve ou não continuar sendo considerado importante, o que é esperado por um determinado grupo para a prática desse trabalho. Uma vez que, de acordo com Bakhtin (1929), cada um de nós orienta suas ações a partir de uma visão de futuro, os conteúdos repetidos nas provas também indicam uma possibilidade de futuro, pois refletem o que é, e deverá continuar sendo considerado importante

\footnotetext{
${ }^{6}$ As provas em cujas análises baseamos esse artigo constituem o processo de seleção realizado em 2004 para provimento de vaga de professor docente I de Língua Espanhola da rede pública estadual do Rio de Janeiro.
} 
no contexto da educação. As provas de seleção transformam certas expectativas sobre o que o professor deveria saber em conteúdos necessários à sua aprovação na seleção, produzindo uma imagem daquele com quem se fala - nesse caso, o professor.

Ao refletirem saberes acumulados ao longo do tempo, apoiando-se em uma memória compartilhada, as provas prescrevem ainda visões de língua e de ensino valorizadas por determinados grupos. Os saberes não possuem em si mesmos uma essência que faça deles elementos fundamentais de figurarem em provas de seleção, ao contrário, é o próprio fato de figurarem em provas de seleção que os legitima como inerentes e necessários de serem "dominados" pelos candidatos.

b- o formulário-ata ${ }^{7}$

Embora este gênero tenha aparentemente finalidade semelhante à de uma ata, seu funcionamento enunciativo se distingue do que correntemente se conhece com tal. Pretende-se que, terminado o preenchimento do formulário, ele se torne o registro de síntese das discussões travadas em reunião, tal qual uma ata do conselho de classe.

Habitualmente, uma ata requer de um único participante da reunião a responsabilidade por redigi-la integralmente. Este deve formalmente lavrá-la, ao final, com sua assinatura, contando ainda com a ratificação dos presentes. Devem constar nela a data, o local e os presentes à reunião. Além disso, o relato das discussões pode vir registrado atribuindo explicitamente cada uma das falas a seus enunciadores ou apenas anotando impessoalmente o conteúdo das discussões.

Em contraposição aos modelos habituais, o formulário-ata aqui analisado tem sua enunciação desmembrada em dois momentos

\footnotetext{
7 Trata-se de documento utilizando frequentemente em uma escola da rede pública estadual do Rio de Janeiro, que se constituiu como cenário de pesquisa desenvolvida por Deusdará (2006).
} 
distintos. O primeiro deles caracteriza-se pela confecção de uma pauta inicial da reunião, seguida de perguntas com espaços determinados para as respostas. Esse texto, cuja elaboração atribuise à direção geral, apresenta-se digitado. É distribuído em todas as salas em que ocorrem reuniões de conselho de classe. O segundo momento configura-se durante a própria reunião do conselho de classe, em que se espera que os professores sigam o roteiro e respondam ao que se propõe. Esse momento exige de um dos participantes da reunião o registro de síntese da discussão.

A partir dos gêneros descritos acima, podemos dizer que captamos espaços em que o professor é avaliado, na situação de candidato a uma vaga em concurso público, e outro em que ele passa a avaliador, na situação de membro de uma reunião de conselho de classe. Ou seja, quando a avaliação não é um poder do professor, pois incide sobre ele.

São esses os gêneros que constituem o material de base para reflexão por nós empreendida no presente artigo. Sua seleção deveuse ao fato de que ambos remetem a atividades que não se vinculam diretamente ao contexto de sala de aula, embora façam menção a ele. Nesse sentido, acreditamos que tal opção apontará para um conjunto de saberes que se pressupõem necessários à prática docente e as relações de poder que os constituem, emergindo de outras coordenadas de espaço-tempo do trabalho do professor.

\section{ATIVIDADE DE AVALIAR E OS SABERES PRESSUPOSTOS}

O paradoxo da avaliação residiria em considerá-la como processo contínuo, articulando temporalidades no espaço escolar, mas também legitimando certos saberes como válidos e necessários. Põe em funcionamento toda uma maquinaria que associa práticas discursivas (a partir de estratégias de fazer dizer) a regimes de 
visibilidade (que fazem ver os resultados produzidos por essa maquinaria disciplinar).

Iniciamos nossas observações tratando da prova. Ressalte-se que os documentos que normalizam a seleção abrangem, além da prova, o edital e o manual do candidato. Não obstante as menções eventuais aos três documentos, neste artigo, centramos nossas análises nas provas de seleção.

Conforme Vivoni (2003), nos concursos realizados pela SEE/RJ, a elaboração das provas insere-se em um processo de diálogo entre essa Secretaria e a FESP - fundação responsável pelo referido concurso. Em um primeiro momento, a secretaria fornece o perfil de docente que deseja selecionar e outras informações relativas ao tipo de prova e ao grau de dificuldade. O tipo de prova e o grau de dificuldade, de alguma maneira, têm de prever uma hierarquização, permitindo dividir os candidatos em aprovados ou eliminados, em classificados ou não classificados.

É de responsabilidade da banca também confeccionar o gabarito de respostas e avaliar seu grau de dificuldade no momento da elaboração. "O perfil do candidato é delineado, num primeiro momento, pela SEE e transmitido à FESP, que o repassa à coordenação acadêmica, que, por sua vez, entra em contato com a banca" (VIVONI, 2003, p. 26).

$\mathrm{Na}$ enunciação de uma prova, legitima-se daquele que pode perguntar e prever as respostas esperadas e de outro que deve inserir-se nas previsões de respostas. A prova também se apresenta como dispositivo de fazer ver graus variados de "domínios" dos conhecimentos requeridos. Trata-se, portanto, de "um saber sobre os indivíduos que nasce da observação dos indivíduos, da sua classificação, do registro e da análise dos seus comportamentos, da sua comparação, etc" (FOUCAULT, 2005, p.121).

Desse modo, indicamos marcas linguístico-discursivas de certos perfis de candidatos construídos, bem como uma hierarquização dos 
saberes que se julgam necessários à aprovação e classificação do candidato.

Reproduzimos a seguir uma das questões constante na prova analisada:

\begin{tabular}{|l} 
Pregunta 35 \\
"...vendrán ochenta o noventa a cenar, ...": \\
(L.12) - ochenta y noventa es la forma escrita de \\
los numerales 80 y 90 . Señale la de los numerales \\
16 y $28:$ \\
a) dieceséis y veinteocho \\
b) diez y seis y veinte y ocho \\
c) dieciséis y veintiocho \\
d) deciséis y ventiocho
\end{tabular}

Apesar de haver um fragmento de texto no comando da questão, verificamos que a presença desse enunciado é completamente desnecessária, uma vez que a questão trata apenas da identificação da correta ortografia dos números 16 e 28.

Para cada questão há apenas uma única resposta verdadeira, as outras três são falsas. Tem-se que os saberes necessários à prática docente já estariam dados previamente, prontos em algum lugar e a tarefa do candidato nessa prova é identificá-los. Aqueles que melhor conhecerem o gênero discursivo em questão e forem capazes de "encontrar" o maior número de "verdades", ou seja, que demonstrarem não só conhecer, mas saber desviar de "ciladas", respostas falsas, mostram-se aptos a tornarem-se professores da rede pública estadual. Esses modos de enunciação próprios às questões de múltipla escolha aproximam-se de um aperfeiçoamento autoritário. O que importa não é compreender a injunção, mas perceber o sinal, reagir logo a ele, de acordo com um código mais ou 
menos artificial, estabelecido previamente, que se traduz na própria opção pela prova de múltipla escolha (FOUCAULT, 2004).

As provas legitimam o controle, dizem quem pode ou não pode continuar na escola, quem pode ou não "passar de ano", quem pode ou não ser professor da rede pública estadual. Punem e recompensam, levam a "autorizações", como poder entrar de férias, passar de ano, exercer a profissão etc.

Outrossim, a presença de saberes acadêmicos, sobretudo gramaticais, em uma prova de seleção constitui movimento circular de interlegitimação: ao pôr em cena questões de gramática, a prova atende a uma expectativa prévia, que circula no social, de que um bom professor de língua (materna ou estrangeira) deve demonstrar habilidades com saberes gramaticais. Assim sendo, legitima não só essa expectativa, como esse campo de saberes, ao mesmo tempo em que também se coloca como instrumento de avaliação. A avaliação apenas reforça o que já se encontra cristalizado.

As "luzes" que iluminam conhecimentos gramaticais ocultariam quais outros saberes não enunciados? Que questões do cotidiano docente deixam de ser problematizadas? Que tensões são ocultadas? Ainda que não tenhamos respostas para estas questões, se retomamos a proposta de Foucault, que os campos poder / saber devem ser compreendidos como resultados de embates políticos e jogos de força, a análise de tais resultados, é relevante. É possível destacar algumas concepções de ensino representantes de crenças, que, dessa forma, se perpetuam no âmbito do ensino de língua em nosso estado: basta conhecer a gramática da língua ensinada para que se tenha sucesso em sala de aula.

Em suma, a naturalização do processo seletivo, aqui representado pelas provas, já é, por si só, um exemplo do vigiar típico da sociedade disciplinar. A vigilância é fundamental, no sentido de comprovar se os futuros professores estão se comportando dentro do esperado para fazer com que o sistema funcione. 
No que se refere ao formulário-ata, observa-se encenação de um diálogo entre a Coordenação da escola e os professores reunidos em conselho de classe. Além da pauta da reunião, as perguntas constituem-se em uma expectativa, ou seja, são uma previsão do que os professores devem discutir. Uma orientação que torna mais útil o aproveitamento do tempo. Evita desperdícios.

Não só as perguntas, mas o espaço reservado e limitado, apresentado em seguida de cada uma das perguntas, também parece funcionar como mecanismo de controle do tempo. A despeito do que habitualmente se conhece por ata de reunião, esta não permite 0 registro das discussões; anotam-se apenas os resultados, objetivando-os nas linhas destinadas a cada uma das questões.

Além disso, perguntas como "11. Alunos que se destacaram pela participação, independente da nota" pressupõem um professor que vigia e controla a produção de seus alunos, durante todo o tempo, possui formas de observação e registro situados para além dos resultados das provas. Com isso, institucionalizam-se práticas de controle individualizantes mantendo os alunos em constante vigilância. É preciso identificar, anotar, distinguir, julgar todo o tempo. A observação não deve cessar. Em relação ao trabalho docente, é necessário extrair dele o máximo de utilidade. Quanto mais observa, mais se torna útil, tanto mais é produtor de saberes de vigilância.

Essa dinâmica de vigilância contínua esperada do professor pressupõe uma dada organização do seu trabalho. Vejamos as questões de número 5 e 6 :

5. A turma está correspondendo ao que você, professor, planejou para o $2^{\circ}$ bimestre?

6. Há falta de interesse por parte de alguns alunos, ou de algum grupo em especial?

Haveria assim, em primeiro lugar, um planejamento de suas ações anterior à interlocução com os alunos e sua execução em sala 
de aula. Nesse modelo, o diálogo que os alunos mantêm com as expectativas elaboradas pelo professor é interpretado como respostas deles ao seu planejamento. Na execução do planejamento, a interlocução dos alunos é compreendida como um "comportamento" que manifestaria interesse ou falta dele em relação ao proposto. Instituem-se lugares bem definidos, com expectativas bastante nítidas, para o diálogo professor-aluno: ao professor cabe, na solidão da elaboração do planejamento, prever e determinar o que será proposto, aos alunos cabe interessar-se por isso ${ }^{8}$.

Emerge desse tipo de expectativa um conjunto de saberes sobre a aprendizagem, o comportamento, sobre os indivíduos. Se o interesse é observado continuamente no comportamento de cada um dos alunos, os supostos "problemas" são, portanto, individualizados. O que se espera do professor é exatamente saber fazer esse tipo de recorte, ou seja, saber indicar a cada lugar um indivíduo e a cada indivíduo seu problema.

O formulário-ata, com seu resultado "objetivado" no funcionamento de perguntas e respostas, garante o aumento do controle. Não é mais preciso ler atas detalhadas da discussão realizada na reunião de Conselho de Classe. Este funcionamento discursivo produz duas imagens do trabalho docente que, aparentemente, se contradizem, mas que se complementam.

De um lado, uma imagem de professor-detento, que tem o tempo de sua atividade controlado. Este controle não se exerce por

\footnotetext{
${ }^{8}$ Como observou Rocha (2001), nas escolas "a luta dos educadores está prioritariamente situada nas turmas, com cada aluno, buscando compreender suas faltas ou estabelecer novos dispositivos de contenção" (ROCHA, 2001, p. 219). Segundo a autora, esse modo de funcionamento do cotidiano gera desgaste físico e psíquico nos profissionais, ao passo que as condições de realização e os modos de gestão do trabalho escolar não ganham visibilidade. Desse modo, o projeto educacional se institui a partir de uma visão clínico-assistencial, em que crianças e adolescentes são observados isolados do contexto. Nesse modelo, individualizam-se os conflitos, atribuindo-se ao profissional a função de diagnosticá-los e propor tratamentos.
} 
um poder que impeça a discussão, mas por inúmeras perguntas que orientam e procuram extrair o máximo de utilidade da reunião.

Além disso, essa detenção do professor se manifesta também no fato de haver, ao mesmo tempo, nove reuniões de Conselho de Classe sendo realizadas: para cada um dos três turnos (manhã, tarde e noite), há uma reunião para cada uma das séries $\left(1^{a}, 2^{a}\right.$ e $3^{a}$ do Ensino Médio). Assim sendo, nenhum dos professores em cada uma das reuniões sabe do que está sendo discutido nas demais salas. Essa "não visibilidade" mútua entre os professores aproxima-se da arquitetura do panóptico, cujos detentos não se vêem mutuamente, nem mesmo àquele que teria como função vigiá-los. Contudo, todos sabem que estão (ou podem estar) sendo vigiados. Não há necessidade da presença da Orientação pedagógica ou da Coordenação da escola, todos preenchem os formulários como se todos eles viessem a ser lidos por quem os elaborou.

Mesmo que esta leitura não se realize, a vigilância se mantém, afinal, "o Panóptico é uma máquina de dissociar o par ver-ser visto" (FOUCAULT, 2004b, p. 167). A vigilância, portanto, deve sempre funcionar. A sujeição independe da existência de alguém no anel central.

"Há uma maquinaria que assegura a dissimetria, o desequilíbrio, a diferença. Pouco importa, conseqüentemente, quem exerce o poder. Um indivíduo qualquer, quase tomado ao acaso, pode fazer funcionar a máquina" (FOUCAULT, 2004b, p. 167).

De outro lado, constitui-se a imagem do professor-carcereiro, aquele que produz um enraizamento do poder. Leva-o ao detalhe, à observação minuciosa, capaz de anotar cada alteração. Conhece os alunos pela série, em cada série, sua turma, em cada turma seu número, a cada número a presença diária, o rendimento nos testes e 
provas, o comportamento cotidiano. Todas essas informações estão detalhadamente registradas em seu diário de classe ${ }^{9}$.

Ao professor-carcereiro, é dada a possibilidade de reconhecer um bom rendimento atribuindo pontos por comportamento, por exemplo, bem como punir, com retiradas de sala, advertências. É ele quem registra indisciplinas (cf. com o item "8 Há problemas de indisciplina que mereçam ser registrados?"). Mais do que a punição propriamente, sua presença deve explicitar toda a maquinaria de vigilância que controla o movimento mais sutil dos corpos. Individua comportamentos e rendimentos, gratifica-os e os pune.

Assim, a produção de saberes de vigilância está vinculada a uma dupla estratégia: o professor exerce a vigilância e, simultaneamente, funciona como uma engrenagem das técnicas de disciplinarização.

No formulário-ata, há duas perguntas propondo uma análise da turma. Vejamos:

4. Conceituação da turma em relação ao $1^{\circ}$. bimestre:

Quanto ao rendimento:

Quanto à freqüência:

Quanto à disciplina:

O que se espera do professor na conceituação da turma quanto ao rendimento? Habitualmente, o rendimento de que trata a escola se extrai de avaliações de conteúdo ou de certas habilidades necessárias ao desenvolvimento de uma tarefa. Codifica-se tal rendimento em números ou letras. Desse modo, ao solicitar o rendimento da turma, é provável que se tenha como resposta algo que tome por base a média dos rendimentos individuais dos alunos da referida turma. Da

\footnotetext{
${ }^{9}$ Aparentemente instrumento de vigilância dos alunos, o diário de classe representa também uma vigilância de si por parte do professor. Assegura, com registro da presença do aluno, a sua própria permanência em sala no horário previsto.
} 
mesma maneira, a frequência controlada no diário refere-se à presença individual na escola. Uma frequência oscilante ou estável de uma determinada turma, nos termos propostos, verifica-se pela média de presenças dos alunos averiguadas em um período determinado. Isso nos leva a perceber que a noção de turma parece funcionar habitualmente como sinônimo de somatório de indivíduos. É preciso ver no grupo o movimento de cada um, vigiá-lo, agir sobre ele, controlando-o.

Desse modo, os saberes necessários à prática docente que atravessam tanto as provas como o formulário-ata restringem-se à vigilância, propõem um profissional que faz ver em cada indivíduo corpos dóceis, ou problemáticos.

\section{CONSIDERAÇÕES FINAIS}

A sobrevalorização dos instrumentos de avaliação na atualidade moveu-nos a produzir esse encontro entre reflexões sobre prova de seleção ao magistério e formulário-ata de conselho de classe. Tratase de materiais aparentemente muito distintos, no entanto, integram uma maquinaria que põe em funcionamento controles e distinções no cotidiano escolar.

A partir do encontro entre os referenciais de autores como Bakhtin e Foucault, percorremos algumas pistas para a construção de imagens de professor e observação de um exercício de poder que age por recompensa e sanção. Uma pista dessa convergência é o privilégio aos saberes enciclopédicos. No caso dos formulários, esses saberes não são explicitados, mas é possível pressupor a importância conferida a eles através do destaque dado aos resultados obtidos pelos alunos. Outro aspecto importante desse privilégio aos saberes enciclopédicos é a dinâmica que impõe às experiências concretas. Nas provas, há um silenciamento de tais experiências. Já no formulárioata, estas aparecem secundarizadas, quando se refere aos alunos que 
teriam se destacado "pela participação, independente da nota". A participação aparece como concessão àqueles que não atenderam à performance esperada.

Outra questão instigante nas análises refere-se às imagens de trabalhador-docente que se produzem a partir das relações de podersaber que atravessam tais discursos. As imagens de professordetento e professor-carcereiro pretendem dar visibilidade a um modo de operar da disciplina, que nos fala de uma complexa economia de exercício do poder. Não há como exercer poder sem se submeter às suas amarras.

Que resposta poderíamos oferecer à sobrevalorização dos instrumentos de avaliação como "solução" para a melhoria da qualidade da Educação? Indicamos que a excessiva valorização dos conhecimentos formais e enciclopédicos dá visibilidade à escola como instituição de seleção e hierarquização de saberes. Apaga-se a ancoragem sócio-histórica e o caráter circunstancial próprio a todos os saberes.

No modelo de educação assentado na performance do aluno (e do professor), o destaque conferido aos resultados, medidos a partir de instrumentos que avaliariam o grau de saberes acumulados por cada um evidencia a aprendizagem como atividade individual, fazendo das experiências coletivas, inscritas em situações concretas, realidades descartáveis. Ou seja, o sentido de qualidade assumido por tais propostas apenas reforça o que já se sabe há muito na escola. Trata-se de consideração a relação com o conhecimento como mera transmissão/aquisição de informação. Os índices alcançados apenas indicam maior quantidade de informações adquiridas, atingem-se os patamares previstos pelas próprias avaliações. 0 movimento gerado é fundamentalmente o de controle e o de interlegitimação, como vimos sustentando ao longo do artigo.

Nesse cenário, quais seriam os desafios colocados para a formação de professores? Enfatiza-se a procura por cursos de 
formação continuada, por metodologias de reforço das informações a serem adquiridas por cada série. Se não é a legitimidade desses cursos que colocamos em questão, o que nos interessa interrogar é a compreensão do cotidiano como mero espaço-tempo de aplicação desses saberes. A nosso ver, trata-se, antes, de confronto, readequação, criação de outros modos de lidar com esses saberes, valorizando a prática profissional como momento de elaboração/criação de um caminho singular com o saber, em vez de tratar-se apenas de reprodução de um "já aprendido". Desse modo, nossas reflexões poderiam indicar elementos para formação de professores priorizando o cotidiano da prática profissional como fonte de saberes. Se o que ganha destaque com as políticas públicas em vigor é um concepção de cotidiano como espaço-tempo de execução de metas e aplicação de conteúdos aprendidos fora dele, o que pretendemos é ressignificar as fronteiras entre o que precede a prática profissional e o que se realiza no cotidiano de trabalho. Apenas cumprir metas pode nos impor uma dinâmica arriscada de aprisionamento aos dispositivos de controle, em que o que se perde é exatamente um caminho singular com o conhecimento. A ênfase conferida às avaliações acaba por desqualificar os saberes oriundos das experiências concretas, uma vez que, como vimos indicando, restringe os sentidos de "qualidade" a alcançar os patamares propostos por esses próprios instrumentos. Pensar a formação de professores na atualidade passa por questionar a limitação do tom atribuído às avaliações de desempenho.

\section{REFERÊNCIAS BIBLIOGRÁFICAS}

BAKHTIN, M. Estética da Criação Verbal. Trad. de Maria Ermantina Galvão. São Paulo: Martins Fontes, 2000.

DALBEN, A. I. L. de F. (Org.). Avaliação da implementação do projeto político pedagógico Escola Plural. Belo Horizonte: UFMG/FAE/GAME, 2000. 
DELEUZE, G. Conversações.Trad. de Peter Pál Pelbart. São Paulo: Ed. 34, 2006.

. Foucault. São Paulo: Brasiliense, 1998.

FOUCAULT, M. A verdade e as formas jurídicas. Trad. de Roberto Machado e Eduardo Morais. Rio de Janeiro: Nau Editora, 2005.

. Vigiar e Punir: nascimento da prisão. Trad. de Raquel Ramalhete. Petrópolis: Vozes, 2004.

Em defesa da sociedade. Trad. de Maria Ermantina Galvão. São Paulo: Martins Fontes, 2002.

GIORGI, M. C. Seleção para a rede pública estadual de ensino: o que se espera do professor de língua estrangeira? Dissertação (Mestrado em Letras), Instituto de Letras, UERJ, Rio de Janeiro, 2005.

MAINGUENEAU, D. Análise de textos de comunicação. Trad. de Cecília Souza-e-Silva e Décio Rocha. São Paulo: Cortez, 2001.

MANCEBO, D.; ROCHA, M. L. "Avaliação na Educação Superior e trabalho docente". In: Interações. São Paulo, v. VII, n. 013, 2002, p. 55-75.

BRASIL. Parâmetros Curriculares Nacionais. Rio de Janeiro: DP\&A, 2002.

REVEL, J. Michel Foucault: conceitos essenciais. São Carlos: Claraluz, 2005.

ROCHA, D; DAHER, M. del C. F. G.; SANT'ANNA, V. L. de A. "Produtividade das investigações dos discursos sobre o trabalho" In: FAÏTA, D.; SOUZA-e-SILVA, M. C. P. de. (org.) Linguagem e Trabalho: construção de objetos de análise no Brasil e na França. São Paulo: Cortez, 2002.

ROCHA, M. L. da. "Educação e Saúde: coletivização das ações e gestão participativa" In: MACIEL, I. (org.) Psicologia e Educação: novos caminhos para a formação. São Paulo: Ciência Moderna, 2001

VIVONI, R. 2003. Interlocução seletiva: análise de provas para seleção de docentes - A construção do perfil do profissional professor. Dissertação (Mestrado em Letras), Instituto de Letras, Rio de Janeiro. 